\title{
IDENTIFICAÇÃO DE ÁREAS HIDROLOGICAMENTE SENSÍVEIS POR MEIO DE MODELAGEM HIDROLÓGICA E DA DISTRIBUIÇÃO ESPACIAL DE SOLOS E VEGETAÇÃO EM AMBIENTES HIDROMÓRFICOS
}

\author{
Identifying hydrologically sensitive areas through hydrological \\ modelling and the spatial distribution of soil and vegetation in hydromorphic environments
}

Cesar Augusto Crovador Siefert

Universidade Federal do Paraná, Curitiba, Paraná, Brasil

cesarsiefert@ufpr.br

Irani dos Santos

Universidade Federal do Paraná, Curitiba, Paraná, Brasil

irani@ufpr.br

Artigo recebido em 30/01/2014 e aceito para publicação em 02/02/2015

RESUMO: Este artigo apresenta metodologia baseada na dinâmica de processos hidrogeomorfológicos e na relação solo-vegetação para estabelecer o limite de sensibilidade hidrológica da paisagem e identificar as áreas hidrologicamente sensíveis (AHS) na bacia hidrográfica do rio Pequeno, PR $\left(104 \mathrm{~km}^{2}\right)$. As AHS são áreas da bacia hidrográfica que possuem uma maior probabilidade de atingirem o estado de saturação do solo, delimitadas espacialmente a partir da definição de um limite de sensibilidade hidrológica. Aplicouse o TOPMODEL para a simulação do processo chuva-vazão em escala diária durante o período de 01/08/1983 a 30/11/2010. Os resultados da simulação indicam que as áreas saturadas são extremamente dinâmicas e sensíveis às condições climáticas, com rápida resposta a precipitação e com recessões abruptas em pequenos períodos de estiagem. Foram definidas como AHS as zonas ripárias da bacia, identificadas pela presença de solos hidromórficos e vegetação hidrófila/higrófila. Como estas áreas apresentam probabilidade de saturação igual ou superior a $90 \%$, este valor foi definido como o limite de sensibilidade hidrológica. As AHS identificadas mediante este limite compreendem 20,5\% da área total da bacia. Os resultados deste trabalho permitem estabelecer uma forma de delimitação das AHS considerando a integração de condicionantes naturais na paisagem.

Palavras-chave: Áreas hidrologicamente sensíveis. Limite de sensibilidade hidrológica. Área variável de afluência. TOPMODEL.

\begin{abstract}
This paper presents a methodology based on hydrogeomorphological process dynamics and the related soil-vegetation to establish the hydrological sensitivity limit of the landscape and identify hydrologically sensitive areas in the Pequeno River watershed, PR $\left(104 \mathrm{~km}^{2}\right)$. Hydrologically sensitive areas (HSA) are defined as areas in a watershed that have a greater probability of reaching soil saturation and generating runoff via variable source areas. HSAs are spatially delimited by the definition of a hydrological sensitivity limit. TOPMODEL was used to simulate the rainfall-runoff process on a daily scale from $08 / 01 / 1993$ to $11 / 30 / 2010$. The simulation indicates that variable source areas are extremely dynamic and sensitive to
\end{abstract}


climate conditions, with a rapid response to rainfall and abrupt recessions in short periods of drought. In this paper, hydrologically sensitive areas were defined as the riparian zone of a watershed, identified by the presence of hydromorphic soils covered by hydrophilous or hygrophilous forest. As this area presented a saturation probability equal or superior to $90 \%$, this value was defined as the hydrological sensitivity limit. The HSA identified by this limit consists of $20.5 \%$ of the watershed's total area. The results of this paper permit us to establish a way of delimiting the HSA considering the integration of natural features in the landscape.

Keywords: Hydrologically sensitive areas. Hydrological sensitivity limit. Variable source area hydrology. TOPMODEL.

\section{INTRODUÇÃO}

Compartimentar a paisagem envolve a sua fragmentação em unidades espaciais conceituais delimitadas a partir de critérios específicos expressos na sua morfologia, gênese, composição e estrutura, associação entre sistemas ambientais ou ainda a relação espacial entre feições superficiais (BISHOP et al., 2012). A partir da delimitação dessas unidades de paisagem com base em distintos condicionantes naturais podem-se identificar fragilidades e potencialidades associadas, estabelecendo-se assim áreas prioritárias de conservação e preservação.

Buttle et al., (2005) afirmam que os métodos de determinação das unidades de preservação utilizados até então sofrem da falta do entendimento dos processos hidrológicos que irão controlar a produção de água, sedimentos e transporte de nutrientes e quais as implicações destes processos nos ambientes aquáticos. Creed et al., (2008) destacam ainda a importância das áreas saturadas como um indicador para compreensão dos processos hidrológicos na escala de bacia. Assim, os aspectos hidrológicos possuem um papel importante no planejamento do uso, conservação e preservação da bacia hidrográfica, sendo que o padrão espacial das áreas variáveis de afluência (AVAs) nas paisagens pode fornecer uma base científica para definição e localização de áreas de preservação.

$\mathrm{O}$ reconhecimento das funções das AVAs e o transporte de sedimentos e nutrientes via escoamento superficial, torna a sua identificação e preservação uma maneira eficaz de assegurar a qualidade da água a partir da compreensão dos mecanismos de geração de escoamento superficial, como demonstram os trabalhos pioneiros de Engman (1974) e Hewlett \&
Troendle (1975). Desde então, uma série de trabalhos publicados remetem a relação entre as AVAs e o transporte de sedimentos e poluentes (p.ex.: GBUREK et al., 2000; PIONKE et al., 2000; WALTER et al., 2000; WALTER et al., 2001; GBUREK et al., 2002; HEATHWAITE et al., 2005; OCAMPO et al., 2006; SRINIVASAN \& McDOWELL, 2007; VESTENA et al., 2008) e a utilização das áreas saturadas como indicadores para a delimitação de buffers de preservação em bacias hidrográficas (QIU, 2003; AGNEW et al., 2006; GORSEVSKI et al., 2008; QIU, 2009; WALTER et al., 2009; SIEFERT \& SANTOS, 2010; SIEFERT \& SANTOS, 2012).

Desta forma, o estudo das AVAs possui um interesse ambiental devido ao seu comportamento hidrológico distinto na paisagem, sendo que a partir do seu entendimento surge o conceito de área hidrologicamente sensível (AHS) (WALTER et al., 2000). Consideram-se as AHSs como determinadas áreas da bacia hidrográfica que apresentam maior probabilidade de geração de escoamento superficial por saturação (WALTER et al., 2000; AGNEW et al., 2006; QIU et al., 2013; DALHKE et al., 2013). A descrição do processo de escoamento superficial via AVA estaria ligada às características físicas da paisagem, enquanto o conceito de AHSs trata de uma forma de avaliação e prevenção de impactos negativos na qualidade da água a partir da probabilidade de saturação do solo (AGNEW et al., 2006).

Entretanto, apesar da definição simples, existe grande dificuldade para identificar e delimitar as AHS e adotá-las em planos de manejo de solo e água em bacias hidrográficas, pois não existe consenso sobre qual a metodologia deve ser adotada para o estabelecimento da probabilidade de saturação mínima 
que será utilizada como limiar para o enquadramento enquanto área sensível. Assim, para a classificação de uma área enquanto AHS deve-se atentar para o limite de sensibilidade hidrológica $\left(L_{H S A}\right)$ da bacia hidrográfica (WALTER et al., 2000).

Diversos métodos já foram utilizados no sentido de buscar a melhor maneira para estabelecimento do $L_{H S A}$ podendo ser divididos em duas abordagens principais: (a) delimitação das áreas hidrologicamente sensíveis a partir de características (p.ex. morfométricas) das bacias hidrográficas (p.ex. WALTER et al., 2000; WALTER et al., 2001, AGNEW et al., 2006; GORSEVKSI et al., 2008; QIU, 2009) e, (b) pela avaliação das práticas de uso e manejo utilizadas diretamente nas áreas geradoras de escoamento, ou seja, pela delimitação das áreas críticas de afluência (p.ex. GBUREK et al., 2002; LYON et al., 2006; SRINIVASAN \& McDOWELL, 2007).

Desta forma, este trabalho considerou a primeira abordagem para delimitação das AHS da bacia do rio Pequeno, localizada na região sul do Brasil. Foi realizado o mapeamento empírico dos ambientes hidromórficos considerando a relação solo-vegetação, sendo definidas como AHS as zonas ripárias da bacia, identificadas pela presença de solos hidromórficos e vegetação hidrófila/higrófila. A dinâmica das áreas saturadas foi avaliada pela simulação do processo chuva-vazão no modelo TOPMODEL e o $L_{H S A}$ para a bacia foi definido pela probabilidade de saturação das AHS.

Por fim, o objetivo deste trabalho é identificar e delimitar as áreas hidrologicamente sensíveis da bacia do rio Pequeno a partir da definição do limite de sensibilidade hidrológica da paisagem por meio de modelagem hidrológica e da relação espacial solovegetação em ambientes hidromórficos.

\section{MATERIAL E MÉTODO}

\section{Área de estudo}

A bacia hidrográfica do rio Pequeno localizase na região Sul brasileira (Figura 1), drenando uma área de $104,8 \mathrm{~km}^{2}$ e apresenta altitudes variando de $870 \mathrm{~m}$ a $1274 \mathrm{~m}$ acima do nível do mar. O rio Pequeno é um rio de $5^{\mathrm{a}}$ ordem na classificação hierárquica de Strahler e a densidade de drenagem é de $4,74 \mathrm{~km} / \mathrm{km}^{2}$, ambas as medidas referentes a escala 1:10.000.

Figura 1. Localização e hipsometria da bacia do rio Pequeno
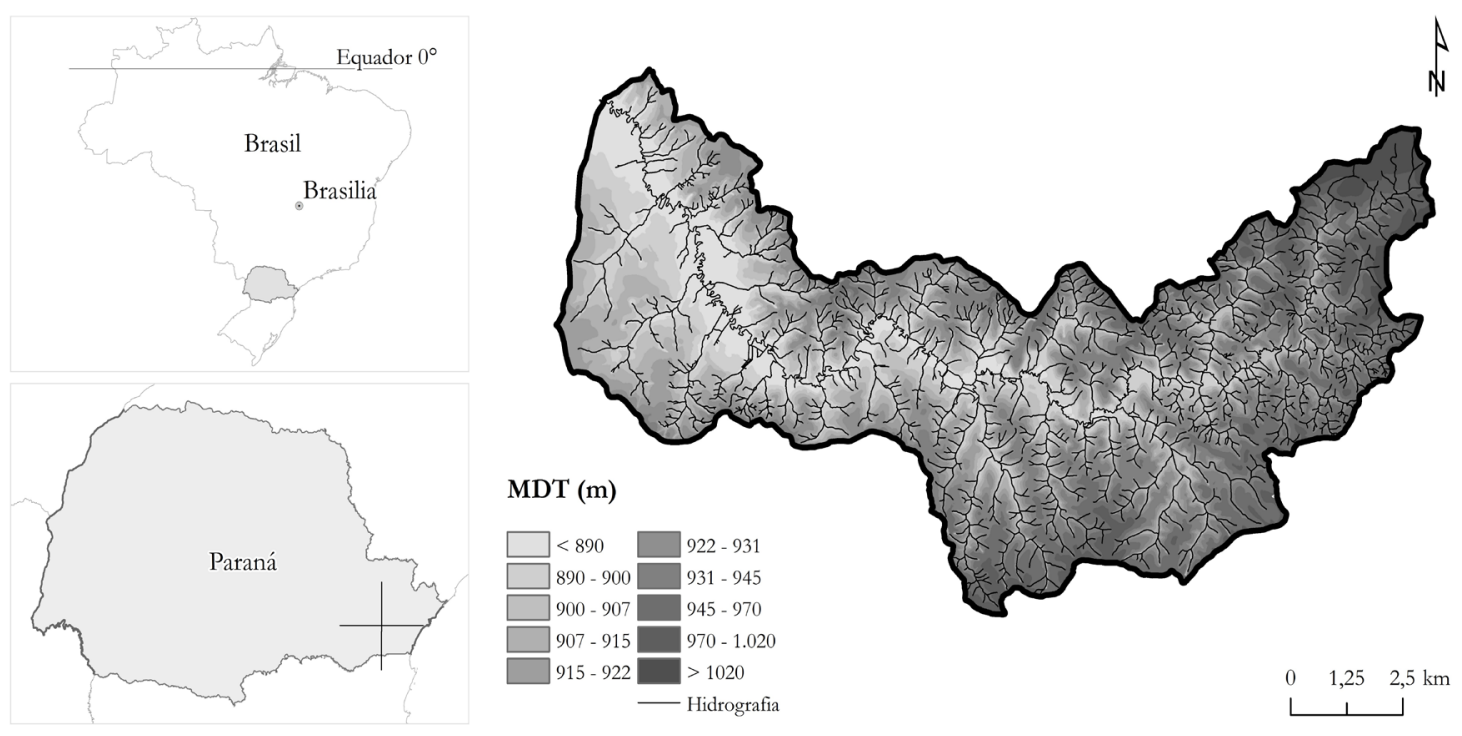

Fonte: os autores, 2013. 
As áreas com maiores declividades estão localizadas na porção nordeste da bacia, normalmente superiores a $20^{\circ}$ de inclinação, com vertentes curtas e vales encaixados, na intersecção das unidades geomorfológicas da Serra do Mar com a área de planalto. Na porção centro-oeste da bacia hidrográfica encontram-se áreas de relevo suave, com a ocorrência de amplas colinas arredondadas e largas planícies fluviais no baixo curso do rio Pequeno, sujeitas a inundação periódica ou permanente.

Nas vertentes mais íngremes desenvolvemse solos rasos e/ou medianamente profundos, com horizontes pouco desenvolvidos e bem drenados. Nas vertentes de relevo suave desenvolvem-se solos com horizontes bem desenvolvidos, de regime não-hidromórfico, profundos, bem drenados e com predomínio de textura argilosa. Nas áreas de deposição fluvial, observa-se ainda a presença de solos de origem hidromórfica, pouco evoluídos, com predominância de material orgânico, resultantes de acumulação de restos vegetais em condições de drenagem restrita (ambientes mal a muito mal drenados) sob presença de vegetação hidrófila ou higrófila.

Com relação ao uso da terra, a bacia apresenta o predomínio de áreas florestadas (48,5\%), contendo vegetação arbórea e arbustiva em geral, na região da Serra do Mar no terço médio e superior. Ao longo da planície de inundação do rio Pequeno, sobretudo nos terços médio e inferior, observam-se usos cujo regime está associado a dinâmica hidrológica, como Vegetação Hidrófila (14,3\%) e Higrófila (2,0\%). Observam-se ainda outras classes de uso como campo $(18,0 \%)$ e agricultura $(10,5 \%)$, fragmentados no terço inferior da bacia, e pequenos fragmentos de reflorestamento $(1,2 \%)$, pastagem $(0,7 \%)$, solo exposto $(<0,1 \%)$, corpos hídricos $(2,7 \%)$ e área urbana $(2,0 \%)$.

\section{Modelagem hidrológica: dinâmica das áreas saturadas}

Para simulação do processo chuva-vazão e dinâmica das áreas saturadas foi utilizado o modelo TOPMODEL 97.01 (BEVEN \& KIRKBY, 1979). A principal premissa do modelo é que, baseado fundamentalmente na distribuição espacial do índice topográfico $-\ln (a / \operatorname{tg} \beta)$ (IT), busca reproduzir o comportamento hidrológico na dinâmica das áreas saturadas em bacias hidrográficas. O IT é um dos principais parâmetros hidrogeomorfológicos utilizados para localização de áreas saturadas na paisagem (BEVEN et al., 1984; MOORE et al., 1991; MÉROT et al., 1995; CURMI et al., 1998; ROHDE \& SEIBERT, 1999; CURIE et al., 2007). O IT é utilizado ainda para caracterizar a distribuição espacial de zonas de saturação superficial, demonstrando os efeitos do relevo na localização e extensão das áreas de acumulação mais propensas a atingirem o estado de saturação hídrica do solo (MOORE et al., 1993).

O TOPMODEL requer séries hidrológicas de vazão observada, precipitação e evapotranspiração potencial. Em virtude da disponibilidade de séries maiores que 25 anos de precipitação e vazão no exutório da bacia hidrográfica do rio Pequeno, optou-se pela utilização do passo de tempo diário na simulação. Os dados de evapotranspiração potencial foram calculados pelo método de Penman-modificado (DOORENBOS \& PRUIT, 1992) com dados de estação meteorológica distante $15 \mathrm{~km}$ da área de estudo. Além dos dados hidrometeorológicos, o modelo requer duas variáveis geomorfológicas como dados de entrada: (I) características de propagação da bacia e (II) distribuição espacial do índice topográfico, obtidas a partir do modelo digital do terreno.

A aplicação do modelo foi realizada para o período de 1/8/1983 a 30/11/2010, totalizando 9.984 dias simulados. A calibração dos parâmetros foi realizada de maneira semiautomática e avaliada a partir do coeficiente de eficiência (COE), proposto por Nash \& Sutcliffe (1970). Além do COE, três outras variáveis foram utilizadas para a análise quantitativa da qualidade da simulação (i) RMSE root-mean-square error, (ii) Percent Bias (PBIAS) e (iii) regressão linear - $\mathrm{R}^{2}$, conforme indicado por Moriasi et al. (2010). Realizou-se ainda a inspeção visual do hidrograma em escala diária comparando os valores de vazão observados e simulados para avaliação do ajuste do modelo.

\section{Mapeamento de ambientes hidromórficos}

Para identificar as zonas ripárias da bacia do rio Pequeno foi realizado um mapeamento empírico 
das áreas úmidas utilizando ortofotos coloridas em escala 1:10.000, com controle de campo para validação da metodologia de interpretação visual com base em atributos fitogeográficos. Foi também realizado um levantamento pedológico exploratório com o objetivo de validar a hipótese da presença de solos hidromórficos nas zonas ripárias, partindo do pressuposto que solos hidromórficos podem ser facilmente identificáveis na paisagem devido as suas características morfológicas (MAUSBACH \& PARKER, 2001) e pela sua posição na paisagem (TINER, 1999).

No processo de identificação e mapeamento de solos hidromórficos observou-se a presença de duas tipologias vegetais distintas nestes ambientes (SIEFERT, 2012). Considera-se que a distribuição da vegetação está relacionada às variações geomorfológicas e pedológicas da paisagem e físico-hídricas do solo, culminando em tipologias vegetais distintas em ambientes cuja saturação do solo é evidenciada. Desta forma, por influência destes fatores abióticos, especialmente no regime hídrico dos solos, podem ser observadas diferentes fisionomias vegetais na zona ripária, compostas por vegetação Hidrófila e Higrófila, conforme definição e descrição das características fisiográficas adotadas por Curcio et al., (2006) para os ambientes fluviais da região.

Caracteriza-se como Hidrófila a vegetação de pequeno porte que apresenta desenvolvimento pleno em áreas de saturação permanente, típicas de ambientes hidromórficos. A vegetação Higrófila, com predomínio de vegetação arbustiva natural, caracteriza-se pelas espécies cujo desenvolvimento ocorre em áreas com regime hídrico de saturação temporária, permitindo assim o estabelecimento de espécies de porte médio típicas de ambientes semihidromórficos.

Conforme a definição de Gregory et al. (1991), zona ripária é a interface entre os ecossistemas terrestres e aquáticos, sendo a sua extensão horizontal espacialmente coincidente ao alcance do predomínio de solos hidromórficos e verticalmente até o dossel da vegetação. Assim, a zona ripária foi identificada mediante a distinção espacial da vegetação das áreas úmidas entre áreas permanentemente saturadas $\mathrm{e}$ temporariamente saturadas. Desta forma, parte-se do pressuposto indicado por Sprecher (2001), de que o mapeamento dos solos hidromórficos é análogo ao mapeamento da vegetação, ou seja, para as áreas onde foi identificada a ocorrência da vegetação hidrófila foi considerado como de predomínio de solos hidromórficos.

Considerando a necessidade de discretização do IT em classes para inserção dos dados topográficos no TOPMODEL, a distribuição espacial do IT obtida pelo MDT foi consistida a partir dos dados do mapeamento das tipologias vegetais, conforme apresentado em Siefert (2012). Assim, considerouse que as áreas de vegetação hidrófila em ambientes hidromórficos apresentam os valores mais elevados de IT, seguidas por aquelas com vegetação higrófila em ambientes semi-hidromórficos. Em termos físicos, isto significa que as áreas de vegetação hidrófila (14,3\% da área total da bacia) são as áreas permanentemente saturadas enquanto que as áreas de vegetação higrófila (1,9\% da área total da bacia) são as primeiras áreas a atingirem o estado de saturação na bacia hidrográfica mediante a ocorrência de um evento de precipitação com volume suficiente para alterar a dinâmica das áreas saturadas.

Considerando a problemática levantada por Agnew et al. (2006) da necessidade de adoção de um atributo físico da paisagem para definição do limite de sensibilidade hidrológica e consequente identificação das AHS, neste trabalho propõe-se a utilização das áreas com a ocorrência de vegetação higrófila na bacia hidrográfica como limiar superior de sensibilidade hidrológica. Assim, para a bacia do rio Pequeno foram consideradas como base para delimitação das AHS as áreas cujas condições pedológicas e topográficas são propícias à ocorrência de vegetação hidrófila e de vegetação higrófila.

Nesta proposta para delimitação do limite de sensibilidade hidrológica da paisagem considera-se que a essência do conceito de AHS é explicitamente geográfica, uma vez que destaca a dependência intrínseca entre os processos hidrológicos e características pedológicas e geomorfológicas das paisagens locais. Considera ainda de que forma estas características influenciam no estabelecimento das tipologias vegetais nas AHS (Figura 2). 
Figura 2. Diagrama conceitual para localização de AHS na paisagem.

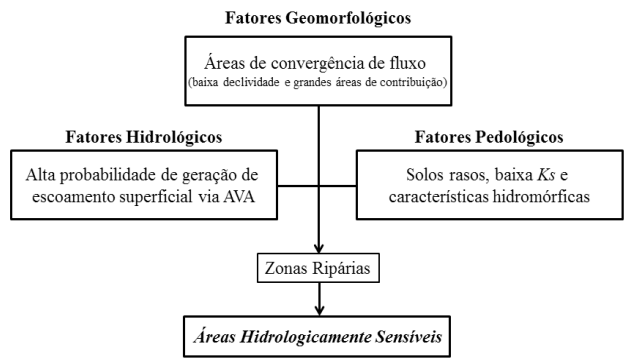

Fonte: adaptado de Siefert, 2012

\section{RESULTADOS E DISCUSSÕES}

Modelagem chuva-vazão e dinâmica temporal das áreas saturadas

A série diária simulada apresentou bom ajuste em relação à série diária observada $(C O E=0,67$; $\mathrm{RMSE}=0,57$; PBIAS $=2,93 \%)$. Em geral, uma simulação hidrológica pode ser julgada como satisfatória se os valores de vazão simulada comparados com os dados da vazão observada atingem valores de $\mathrm{COE}>0,5, \mathrm{RMSE}<0,7$ e o $\mathrm{PBIAS} \pm 25 \%$ (MORIASI et al., 2007). A Figura 3 apresenta o diagrama de dispersão entre os valores de vazão observada e simulada $\left(\mathrm{R}^{2}=0,694\right)$. Uma discussão mais detalhada sobre o processo de calibração realizado e a avaliação dos resultados da modelagem pode ser encontrada em Siefert (2012).

Em geral, o hidrograma simulado apresentou tendência similar à do hidrograma observado, considerando que os picos mostraram-se coerentes na maior parte da série simulada. Em relação às recessões, os dados simulados foram ligeiramente superiores aos dados observados, sobretudo nas vazões observadas abaixo de $1,5 \mathrm{~m}^{3} / \mathrm{s}$.

Deve-se ressaltar esta dificuldade em simular perfeitamente as vazões em bacias hidrográficas, uma vez que podem ocorrer processos hidrológicos na bacia não contemplados nas hipóteses simplificadoras do TOPMODEL (BEVEN, 2002), como por exemplo, a existência de escoamento subsuperficial por caminhos preferenciais ou ausência de conectividade entre as áreas saturadas ou ainda situações desconsideradas no modelo, como por exemplo, tipos de cobertura do solo com respostas hidrológicas distintas e diferentes tipos de solo com diferentes propriedades físico-hídricas.

O hidrograma simulado pode ser considerado satisfatório em virtude das limitações do TOPMODEL considerando dados diários (Figura 3). A vazão média da série simulada é de $3,08 \mathrm{~m}^{3} / \mathrm{s}, 3 \%$ inferior à vazão média observada de $3,17 \mathrm{~m}^{3} / \mathrm{s}$. 
Figura 3. Diagrama de dispersão entre os valores de vazão observada e simulada.

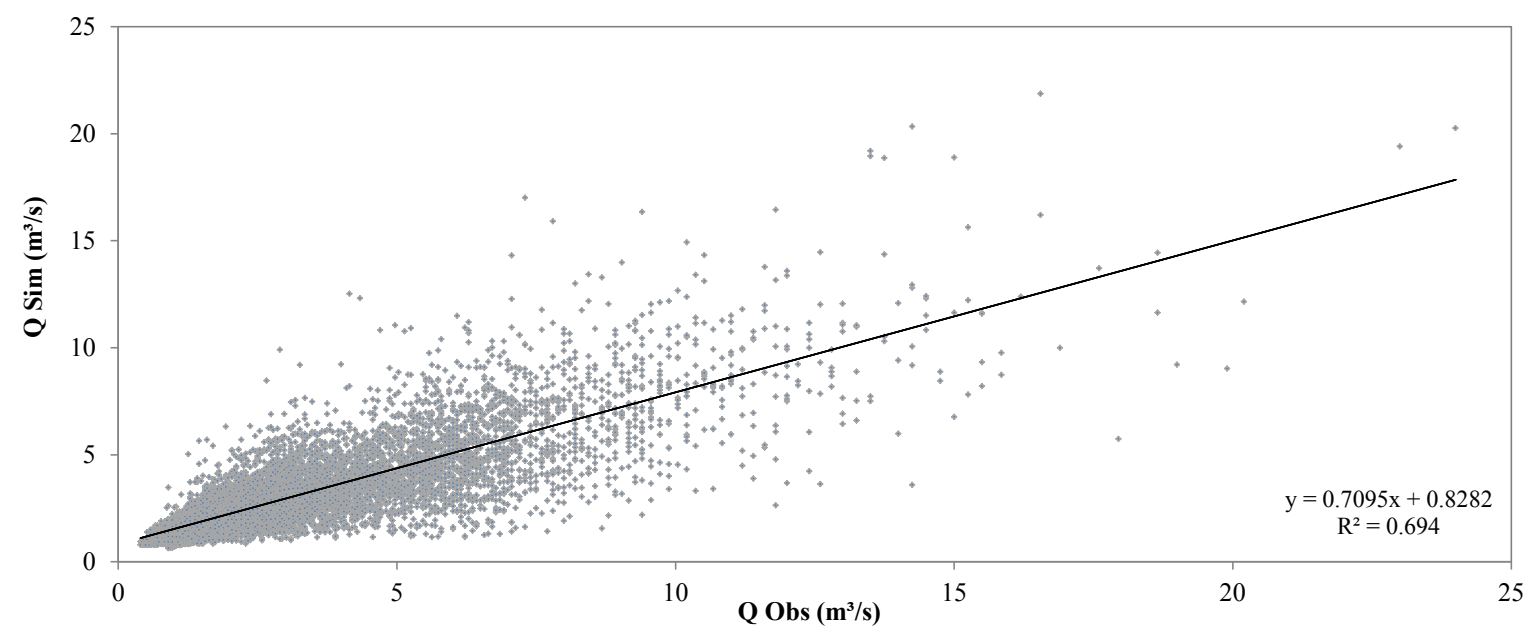

Fonte: os autores, 2013.

Da aplicação do TOPMODEL obteve-se também a porcentagem de áreas saturadas na bacia do rio Pequeno para os 9.984 dias simulados. A dinâmica destas áreas apresentou-se extremamente sensível às variações hidroclimáticas, com resposta rápida à precipitação e com recessões abruptas em pequenos períodos de estiagem. Observou-se no período uma variação da porcentagem de área saturada entre $17 \%$ a $38 \%$ da bacia, configurando-se assim, a fração variável da área saturada ao longo do tempo conforme expresso na teoria da área variável de afluência (CAPPUS, 1960; TSUKAMOTO, 1963; HEWLETT \& HIBBERT, 1963; HEWLETT \& HIBBERT, 1967).

A Figura 4 apresenta a curva de permanência das vazões observadas juntamente com a curva indicativa da dinâmica das áreas saturadas no tempo para o período simulado.

Figura 4. Curvas de permanência das vazões observadas e das áreas saturadas.

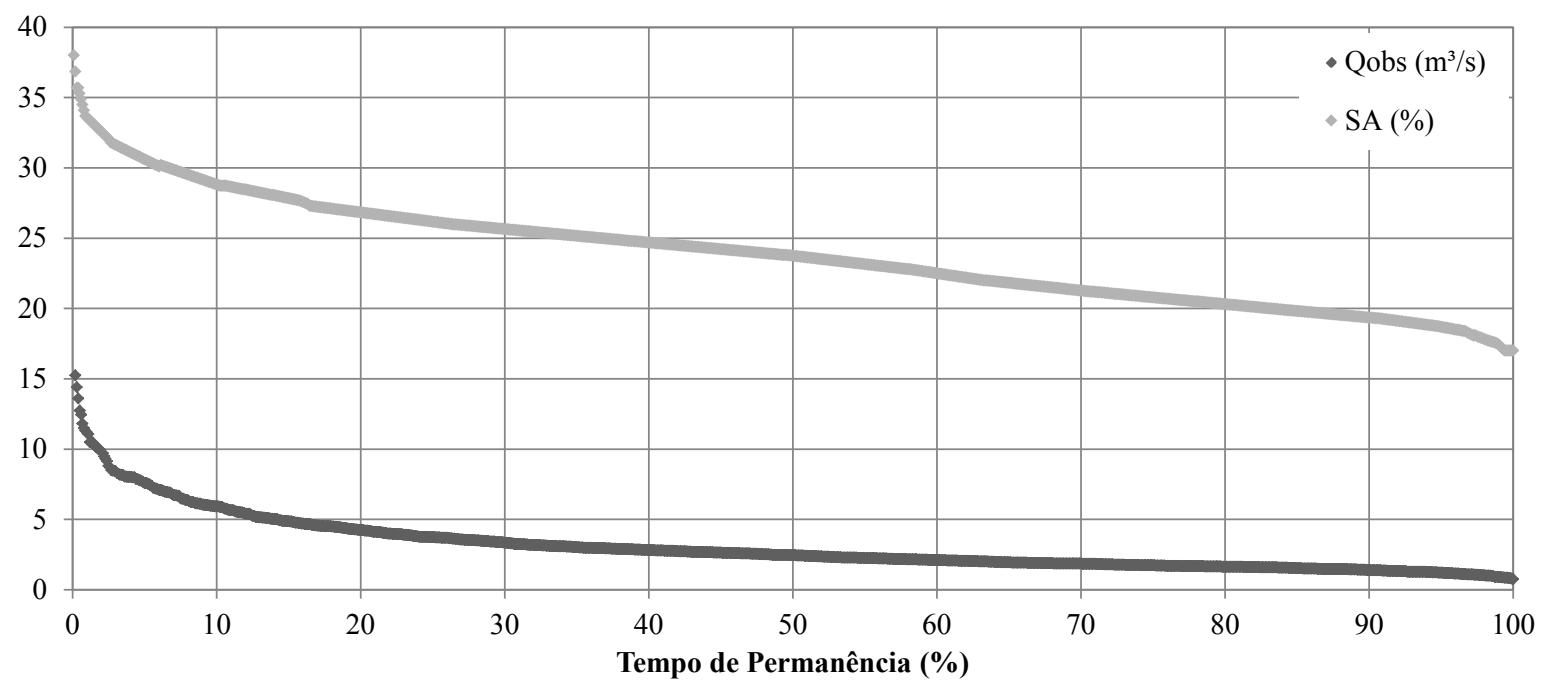

Fonte: os autores, 2013. 
A variação espacial das áreas saturadas observadas na simulação pode ser considerada coerente com as características topográficas da bacia do rio Pequeno devido ao predomínio de largas planícies fluviais e várzeas de inundação caracterizadas por vertentes longas e de baixas declividades ao longo do rio principal. Desta forma, corrobora-se com a ideia do controle exercido pela topografia nos mecanismos de geração de escoamento via áreas saturadas. Na bacia do rio Pequeno as áreas permanentemente saturadas coincidem com as áreas de ocorrência de solos hidromórficos e orgânicos, sendo este resultado de acordo com Richardson et al., (2001) que indicam que em áreas de planície são comumente encontrados solos hidromórficos, devido a estas serem áreas de grande acumulação de fluxo e baixa declividade.

\section{Distribuição espacial da Probabilidade de Saturação $\left(\boldsymbol{P}_{\text {sat }}\right)$}

A distribuição espacial da probabilidade de saturação $\left(P_{\text {sat }}\right)$ para a bacia do rio Pequeno foi elaborado conforme metodologia proposta por Walter et al., (2000). Desta forma, considerou-se que o $P_{s a t}$ é calculado de maneira distribuída para a bacia hidrográfica dado o período em que determinado pixel se encontra saturado em relação ao tempo total, sendo expresso pela relação:

$$
P_{\text {sat }} A_{i}=\frac{\sum n_{\text {sat }}}{\sum n_{t}}
$$

onde $n_{\text {sat }}$ é o número de dias em que o pixel $A i$ encontra-se saturado e produz escoamento superficial, $n_{t t}$ é a quantidade total de dias considerado no período simulado.

Assim, a partir dos dados simulados da dinâmica das áreas saturadas, foi estabelecida a probabilidade de saturação de forma distribuída. $\mathrm{Na}$ análise da relação entre a probabilidade de saturação e a porcentagem de área saturada na bacia do rio Pequeno, nota-se que uma determinada porção da bacia permanece $100 \%$ do tempo saturada, correspondendo aos $17 \%$ de área saturada mínima mencionada anteriormente, e que acima deste valor existe uma dinâmica temporal das áreas saturadas até um máximo de $38 \%$ da área da bacia.

A permanência das áreas saturadas ao longo do tempo pode ser analisada com base na relação entre o valor do índice topográfico que se encontra saturado em um determinado momento da simulação e a $P_{\text {sat }}$ correspondente, conforme Figura 5 (5a). Desta forma, observa-se que os valores de IT que indicam espacialmente as áreas que fazem parte do processo de área variável de afluência variam entre o intervalo 9,3 a 13,0, correspondendo respectivamente, a uma $P_{\text {sat }}$ de aproximadamente $1 \%$ (AS máxima) e $100 \%$ (AS mínima) no tempo simulado. Destaca-se que estes valores de IT associados a $P_{\text {sat }}$ não devem ser extrapolados para outras bacias, pois os valores absolutos de IT são dependentes da resolução do MDT e os valores de $P_{\text {sat }}$ são dependentes das condições hidrológicas locais.

Observa-se na Figura 5 (5b) a ocorrência de três comportamentos distintos na curva de permanência das áreas saturadas. $O$ trecho inicial da curva com $P_{\text {sat }}$ de $100 \%$ representa uma zona de saturação permanente correspondente a uma área de $17 \%$ da bacia. O trecho médio da curva de permanência representa a área de saturação variável, entre $17 \%$ e $38 \%$ da área da bacia. Este trecho pode ser dividido em dois segmentos, sendo que o primeiro apresenta taxa de decaimento constante e uma inclinação próxima a $45^{\circ}$, correspondente as áreas da bacia com regime de saturação mais dinâmico, acionado por eventos pequenos e médios de precipitação. $O$ segundo segmento representa áreas de saturação variável associadas a grandes eventos de precipitação. $\mathrm{O}$ trecho final da curva não consta da figura e representa as áreas de vertente sem saturação, que ocupam $62 \%$ da bacia. 
Figura 5. Relação entre a probabilidade de saturação e (a) respectivos valores de índice topográfico e (b) percentual de áreas saturadas.
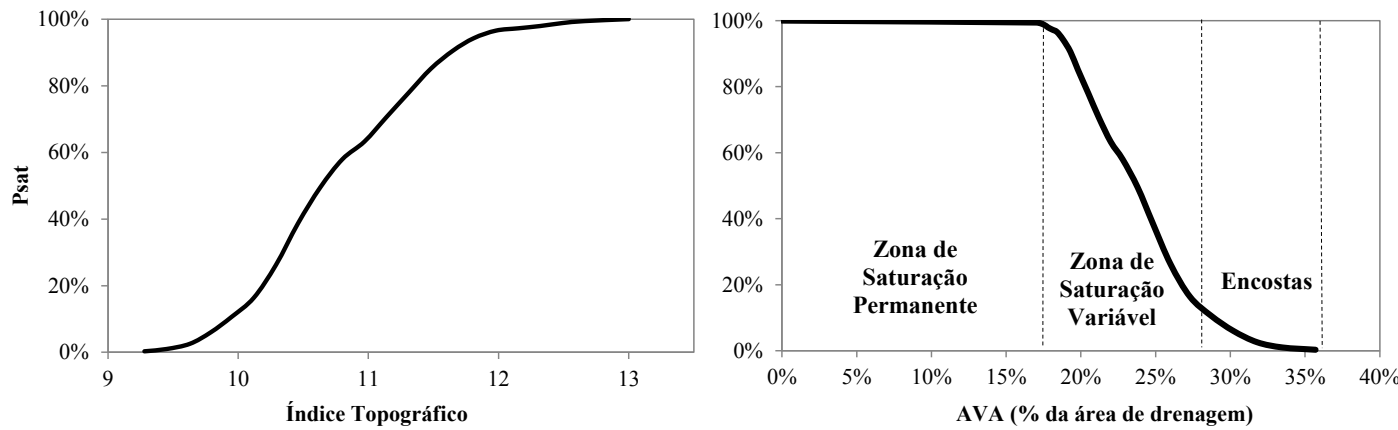

Fonte: os autores, 2013.

Pode-se fazer uma abordagem ligeiramente diferente desta situação ao aproximar os setores identificados graficamente na curva de permanência das áreas saturadas e as unidades de resposta hidrológica (FLÜGEL, 1995). Em relação aos aspectos geomorfológicos da bacia, pode-se afirmar que os $17 \%$ de área relativa a zona de saturação permanente corresponde às planícies de inundação e a área ocupada pelos canais. $\mathrm{O}$ trecho médio da curva corresponde aos terraços fluviais que atingem o estado de saturação de acordo com a magnitude do evento e cuja área saturada varia linearmente com a probabilidade de saturação. A partir de aproximadamente $27 \%$ de área até os $38 \%$ de área referem-se às áreas cuja saturação é rara, localizadas na transição entre as encostas e os vales. As áreas acima de 38\% no gráfico referem-se à porção das encostas e topos de morro na bacia que não atingem o estado de saturação do solo.

\section{Definição do Limite de Sensibilidade Hidrológica para a bacia do rio Pequeno}

Como forma de avaliação do valor ótimo de $P_{\text {sat }}$ a ser utilizado para o enquadramento das AHS na bacia do rio Pequeno analisou-se diferentes proposições de limiar e os efeitos no tamanho e no tipo de uso das áreas da bacia enquadradas como AHS, conforme apresentado na Tabela 1.

Tabela 1. Proposições de $P_{\text {sat }}$ para definição de AHS.

\begin{tabular}{|c|c|c|c|c|c|c|c|c|c|c|}
\hline \multirow{2}{*}{$\begin{array}{l}P_{\text {sat }} \\
(\%)\end{array}$} & \multicolumn{9}{|c|}{ Classes de uso do solo (\%) } & \multirow{2}{*}{$\begin{array}{l}\text { Total } \\
(\%)\end{array}$} \\
\hline & Agric. & Área Urb. & Campo & Floresta & Pastagem & Reflores. & Solo Exp. & $\begin{array}{l}\text { Veg. } \\
\text { Hidr }\end{array}$ & $\begin{array}{l}\text { Veg. } \\
\text { Higr. }\end{array}$ & \\
\hline 1,0 & 4,0 & 1,3 & 5,1 & 8,0 & 0,2 & 0,5 & 0,0 & 14,3 & 2,0 & 35,3 \\
\hline 5,0 & 3,3 & 1,1 & 4,6 & 7,2 & 0,2 & 0,4 & 0,0 & 14,3 & 2,0 & 33,1 \\
\hline 10,0 & 3,0 & 1,1 & 4,2 & 6,5 & 0,2 & 0,4 & 0,0 & 14,3 & 2,0 & 31,7 \\
\hline 20,0 & 2,5 & 0,9 & 3,5 & 5,4 & 0,1 & 0,3 & 0,0 & 14,3 & 2,0 & 28,9 \\
\hline 30,0 & 2,2 & 0,8 & 3,1 & 4,9 & 0,1 & 0,3 & 0,0 & 14,3 & 2,0 & 27,7 \\
\hline 40,0 & 2,0 & 0,8 & 2,8 & 4,5 & 0,1 & 0,2 & 0,0 & 14,3 & 2,0 & 26,6 \\
\hline 50,0 & 1,8 & 0,7 & 2,7 & 4,1 & 0,1 & 0,2 & 0,0 & 14,3 & 2,0 & 25,8 \\
\hline 60,0 & 1,6 & 0,6 & 2,4 & 3,8 & 0,1 & 0,2 & 0,0 & 14,3 & 2,0 & 24,9 \\
\hline 70,0 & 1,4 & 0,5 & 2,2 & 3,5 & 0,1 & 0,2 & 0,0 & 14,3 & 2,0 & 24,2 \\
\hline 80,0 & 1,1 & 0,4 & 2,0 & 2,9 & 0,1 & 0,1 & 0,0 & 14,3 & 2,0 & 22,8 \\
\hline 90,0 & 0,9 & 0,4 & 1,8 & 1,0 & 0,1 & 0,1 & 0,0 & 14,3 & 2,0 & 20,5 \\
\hline 100,0 & 0,0 & 0,0 & 0,0 & 0,0 & 0,0 & 0,0 & 0,0 & 14,3 & 0,0 & 14,3 \\
\hline
\end{tabular}

Fonte: os autores 
Gorsevski et al., (2008) indicam que a implementação de um valor limite para o enquadramento de uma AHS deve variar de acordo com os objetivos do manejo proposto para a bacia em questão. Pode-se observar a existência de relação inversa entre o valor de $P_{\text {sat }}$ e a área total enquadrada como AHS, conforme apontado em Walter et al., (2000). Desta forma uma $P_{\text {sat }}$ igual a $1 \%$ seria mais restritiva à ocupação do que uma $P_{\text {sat }}$ igual a 100\% (Tabela 1).

Os resultados da Tabela 1 mostram que a área permanentemente saturada $\left(P_{\text {sat }}=100 \%\right)$ coincide espacialmente com a área de vegetação hidrófila. Nota-se ainda que a área correspondente a $P_{s a t}$ de $90 \%$ engloba a totalidade das áreas com vegetação hidrófila e higrófila, além de pequenas áreas com outros usos do solo, totalizando aproximadamente $20,5 \%$ da área total da bacia. Neste sentido, destacase a identificação destas áreas com outros usos que, naturalmente, possuem características hidromórficas, sendo possíveis alvos de um manejo de água e solo condizente com as AHS.

Este valor de $P_{\text {sat }}$ de $90 \%$ foi utilizado como base para enquadramento das áreas hidrologicamente sensíveis, uma vez que contempla a totalidade das zonas ripárias na bacia hidrográfica. Além de indicativo para a ocorrência de vegetação hidrófila e higrófila, engloba ainda pequenas áreas com outros usos do solo, mas cuja dinâmica natural permitiria a ocorrência destas tipologias vegetais.

Baseado nos resultados da definição das AHS, determinadas empiricamente a partir do atributo vegetação e pela simulação da probabilidade de saturação, pode-se cotejar os resultados desta pesquisa com algumas propostas realizadas para definição e delimitação das AHS. A Figura 6 mostra um panorama dos diferentes valores de $P_{\text {sat }}$ observados na literatura, sendo que Walter et al., (2000) propõem um valor de $P_{\text {sat }}=30 \%$ e Agnew et al., (2006) um valor de $P_{\text {sat }}=5 \%$ para a delimitação das AHS em bacias hidrográficas. Gorsevski et al., (2008) definem empiricamente que as AHS correspondem as áreas permanentemente saturadas da bacia $\left(P_{\text {sat }}=100 \%\right)$.

Nota-se que o limite de sensibilidade hidrológica adotado para a bacia do rio Pequeno $\left(P_{\text {sat }}=90 \%\right)$ é um valor intermediário com relação aos estudos anteriores, podendo ser considerado como pouco restritivo, tendo em conta que o valor do $P_{\text {sat }}$ e a área enquadrada como AHS são inversamente proporcionais (Figura 6).

Figura 6. Diferentes valores do limite de sensibilidade hidrológica aplicados na bacia do rio Pequeno, PR em relação à área enquadrada como AHS.

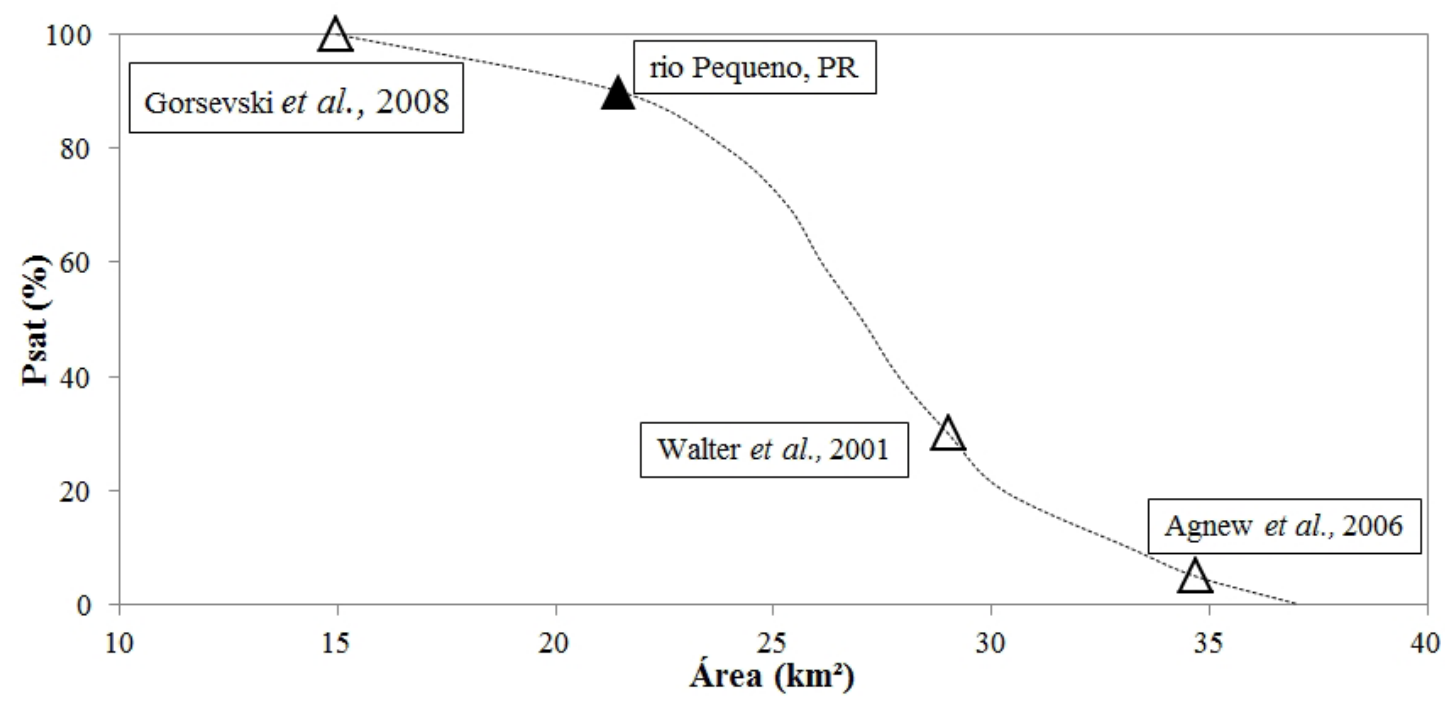

Fonte: os autores, 2013. 
A Figura 7 apresenta o mapa das áreas hidrologicamente sensíveis obtidas para a bacia hidrográfica do rio Pequeno.

Em termos espaciais, pode-se observar que as AHS estão localizadas na planície de inundação do canal principal e dos canais tributários, sendo estas formadas por sedimentos recentes, em solos de regime semi-hidromórficos ou hidromórficos e caracterizadas, em sua maioria, pela presença de vegetação hidrófila e higrófila. Além destas áreas, observa-se também que as AHS mapeadas ao longo dos canais tributários no terço médio e inferior, em sua maioria contemplam também a zona ripária, a exemplo dos buffers das áreas de preservação permanente. Destaca-se ainda que as AHS mapeadas no terço inferior da bacia, sobretudo as áreas a sudoeste e noroeste, coincidem com áreas de ocupação urbana recente.

Figura 7. Mapa das áreas hidrologicamente sensíveis na bacia do rio Pequeno, PR.

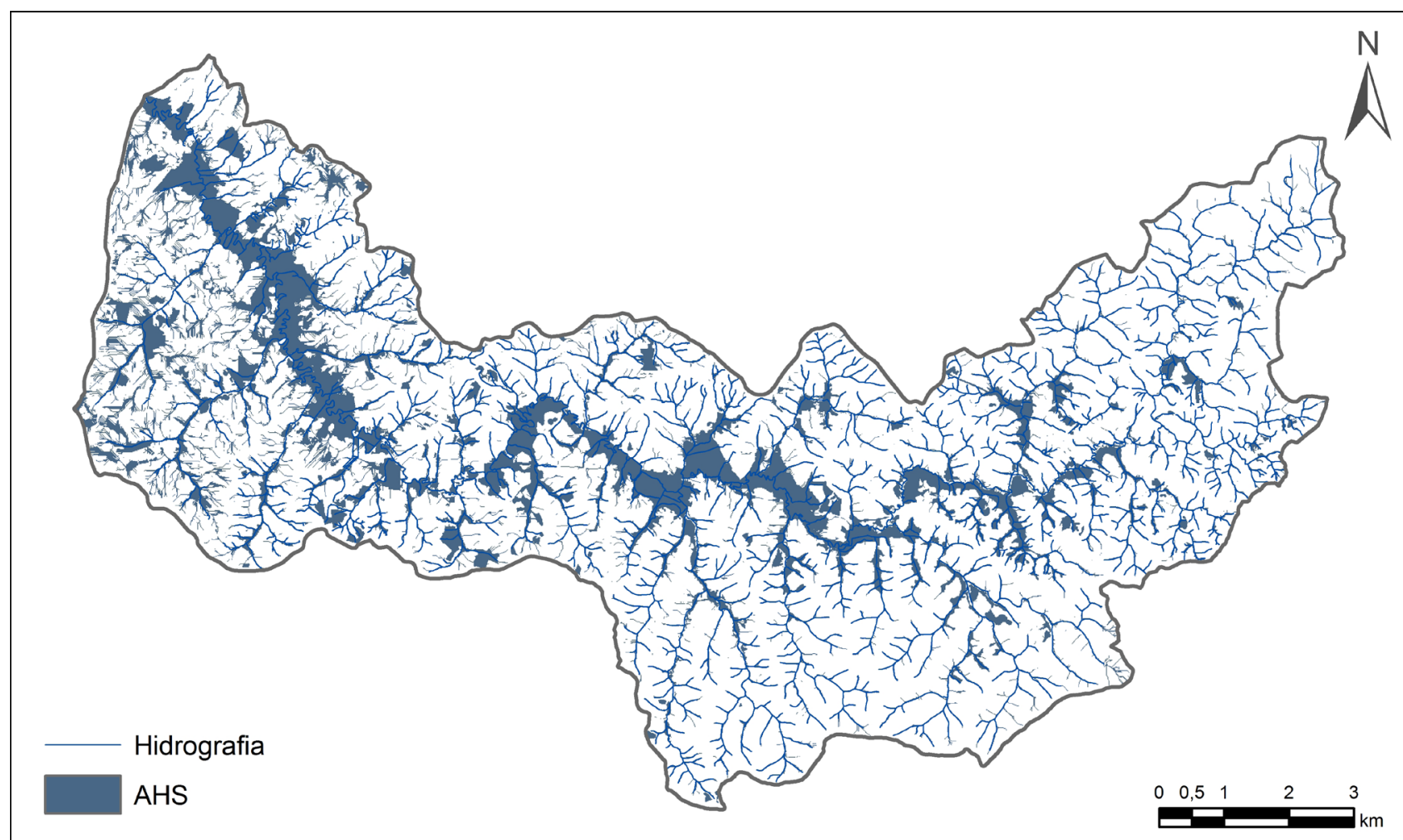

Fonte: os autores, 2013.

\section{CONCLUSÃO}

A identificação das AHS para a área de estudo foi definida com base nas características pedológicas e topográficas, além das características da vegetação sob ambientes (semi)hidromórficos na bacia hidrográfica. Assim, foi definido empiricamente um limite de sensibilidade hidrológica para enquadramento e delimitação destas AHSs na bacia do rio Pequeno, o qual corresponde a uma probabilidade de saturação de
$90 \%$ do tempo simulado. Desta forma enquadraram-se como AHS todas as áreas permanentemente saturadas e as áreas cujo regime hídrico indica saturação do perfil do solo acima de $90 \%$ do tempo, resultando em $20,5 \%$ da área total da bacia.

OTOPMODEL respondeu de forma satisfatória às condições ambientais da bacia hidrográfica e a utilização de séries diárias. A porcentagem de áreas saturadas na bacia em relação a área total variou entre $17 \%$ a $38 \%$. Deste modo, a dinâmica 
de saturação da bacia é extremamente sensível representado pela rápida resposta à precipitação e com recessões abruptas em pequenos períodos de estiagem.

A análise de consistência do IT tornou sua distribuição espacial fisicamente compatível com a distribuição espacial das áreas saturadas da bacia determinadas de forma empírica, eliminando eventuais inconsistências relacionadas à precisão e escala da base cartográfica e ao método de interpolação dos dados topográficos para geração do MDT. Desta forma, pode-se identificar e delimitar as áreas hidrologicamente sensíveis de forma coerente com as características fisiográficas da bacia, uma vez que na simulação da dinâmica das áreas saturadas o tempo em que um determinado local da bacia encontra-se saturado é de fundamental importância para o seu enquadramento enquanto AHS de acordo com o limite adotado.

Por fim, nesta proposta de estabelecimento do limite de sensibilidade hidrológica da paisagem considerou-se que tanto os fatores pedológicos, topográficos e vegetação são elementos cuja dinâmica de alteração ou frequência de estabelecimento são lentos em comparação aos processos hidrológicos. Estes, por sua vez, possuem uma dinâmica fortemente influenciada pelas condições climáticas de modo quesuasensibilidade e resposta a alterações na dinâmica ambiental são produzidas em um tempo cronológico mais rápido que os demais. Entretanto, observou-se a dificuldade em estabelecer um limite fixo para indicação das AHS na paisagem em distintas características fisiográficas, sendo interessante investigar o grau de sensibilidade de bacias hidrográficas mediante o estabelecimento de zonas e graus distintos de sensibilidade em uma mesma bacia hidrográfica.

\section{AGRADECIMENTOS}

O primeiro autor agradece a CAPES pela concessão da bolsa de estudos para desenvolvimento desta pesquisa.

\section{REFERÊNCIAS}

AGNEW, L.J.; LYON S.; GERARD-MARCHANT P.; COLLINS V.B., LEMBO A.J.; STEENHUIS
T.S.; WALTER, M.T. Identifying hydrologically sensitive areas: Bridging the gap between science and application. Journal of Environmental Management, 78, p.63-76, 2006. DOI: http://dx.doi.org/10.1016/j. jenvman.2005.04.021

BEVEN, K.J.; KIRKBY, M.J. A physically based, variable contributing area model of basin hydrology. Hydrological Sciences Bulletin, 24, p.43-69, 1979. DOI: http://dx.doi.org/10.1080/02626667909491834

BEVEN, K.J.; KIRKBY, M.J.; SCHOFIELD, N.; TAGG, A.F. Testing a Physically-based flood forecasting model (TOPMODEL) for three U.K. catchments. Journal of Hydrology, 69, p.119143, 1984. DOI: http://dx.doi.org/10.1016/00221694(84)90159-8

BEVEN, K. Towards an alternative blueprint for a physically based digitally simulated hydrologic response modeling system. Hydrological Processes, 16, p.189-206, 2002. DOI: http://dx.doi.org/10.1002/ hyp. 343

BISHOP, M.P.; JAMES, L.A.; SHRODER JR, J.F.; WALSH, S.J. Geospatial technologies and digital geomorphological mapping: Concepts, issues and research. Geomorphology. 137, p.5-26, 2012. DOI: http://dx.doi.org/10.1016/j.geomorph.2011.06.027

CAPPUS, P. Bassin experimental d'Alrance: etudes dês lois de l'ecoulement. Application au calcul et a la prevision des debits. La Houille Blanche, A, p.493514. 1960.

CREED, I.F.; SASS, G.Z.; WOLNIEWICZ, M.B.; DEVITO, K.J. Incorporating hydrological dynamics into buffer strip design on the sub-humid Boreal Plain of Alberta. Forest Ecology and Management. 256, p.1984-1994, 2008. DOI: http://dx.doi.org/10.1016/j. foreco.2008.07.021

CURCIO, G.R.; UHLMANN, A.; SEVEGNANI, L. A Geopedologia e sua influência sobre Espécies Arbóreas de Florestas Fluviais. Colombo (PR): Embrapa Florestas, 2006. 31p. 
CURIE, F.; GAILlARD, S.; DUCHARNE, A.; BENDJOUDI, H. Geomorphological methods to characterize wetlands at the scale of the Seine watershed. Science of the Total Environment. 375, p.59-68, 2007. DOI: http://dx.doi.org/10.1016/j. scitotenv.2006.12.013

CURMI, P., DURAND, P.; GASCUEL-ODOUX, C.; MÉROT, P.; WALTER, C.; TAHA, A. Hydromorphic soils, hydrology and water quality: Spatial distribution and functional modelling at different scales. Nutrient Cycling in Agroecosystems, 50, p.127-142, 1998. DOI: http://dx.doi.org/10.1023/A:1009775825427

DAHLKE, H. E., EASTON, Z. M., FUKA, D. R., WALTER, M. T., \& STEENHUIS, T. S. Real-Time Forecast of Hydrologically Sensitive Areas in the Salmon Creek Watershed, New York State, Using an Online Prediction Tool. Water, v.5, n.3, p.917-944, 2013. DOI: http://dx.doi.org/10.3390/w5030917

DOORENBOS, J.; PRUIT, W. Crop water requirements. Roma: FAO, 1992. 144p.

ENGMAN, E. T. Partial area hydrology and its application to water resources. Water Resources Bulletin, 10, p.512-521, 1974. DOI: http://dx.doi. org/10.1111/j.1752-1688.1974.tb00592.x

FLÜGEL, W. A. Delineating hydrological response units by geographical information system analyses for regional hydrological modelling using PRMS/ MMS in the drainage basin of the River Bröl, Germany. Hydrological Processes, 9, p.423-436, 1995. DOI: http://dx.doi.org/10.1002/hyp.3360090313

FREY, M.P.; SCHNEIDER, M.K.; DIETZEL, A., REICHERT, P.; STAMM, C. Predicting critical source areas for diffuse herbicide losses to surface waters: role of connectivity and boundary conditions. Journal of Hydrology. 365, p.23-36, 2009. DOI: http://dx.doi. org/10.1016/j.jhydrol.2008.11.015

GBUREK, W.J.; SHARPLEY, A.N.; HEATWAITE, L.; FOLMAR, G.J. Phosphorus Management At The watershed scale: a modification of the phosphorus index. Journal of Environmental Quality, 29, p.130144, 2000.

GBUREK, W.J.; DRUNGIL C.C.; SRINIVASAN M.S.; NEEDELMAN B.A.; WOODWARD D.E. Variable-source-area controls on phosphorus transport: Bridging the gap between research and design. Journal of Soil and Water Conservation, 57, p.534-543, 2002.

GORSEVSKI, P.V.; BOLL, J. GOMEZDELCAMPO, E. BROOKS, E.S. Dynamic riparian buffer widths from potential non-point source pollution areas in forest watersheds. Forest Ecology and Management, 256, p.664-673, 2008. DOI: http://dx.doi.org/10.1016/j. foreco.2008.05.019

HEATHWAITE, A.L.; QUINN, P.F.; HEWETT, C.J.M. Modeling and managing critical source areas of diffuse pollution from agricultural land using flow connectivity simulation. Journal of Hydrology, 304, p.446-461, 2005. DOI: http://dx.doi.org/10.1016/j. jhydrol.2004.07.043

HEWLETT, J.D.; HIBBERT, A.R. Moisture and energy conditions within a sloping soil mass during drainage. Journal of Geophysical Research, 68, p.1081-1087, 1963. DOI: http://dx.doi.org/ http:// dx.doi.org/10.1029/JZ068i004p01081

HEWLETT, J.D.; HIBBERT, A.R. Factors affecting the response of small watersheds to precipitation in humid areas. International Symposium of Forest Hydrology, 275-290, 1967. DOI: http://dx.doi. org/10.1177/0309133309338118

HEWLETT, J.D.; TROENDLE, C.A. Non-point and diffused water sources: a variable source area problem. Proceedings of a Symposium on Watershed Management, 21-45, 1975.

KIRKBY, M.J. (1969) Infiltration, throughflow and overland flow. In: Chorley R.J. Water, Earth and Man. London: Methuen, 215-227.

LYON, S.W.; MCHALE, M.R.; WALTER, M.T.; STEENHUIS, T.S. The impact of runoff generation 
mechanisms on the location of critical source areas. Journal of American Water Resources Association. 42, p.793-804, 2006. DOI: http://dx.doi. org/10.1111/j.1752-1688.2006.tb04493.x

MAUSBACH, J M.; PARKER, W.B. Background and History of the concept of hydric soils. In: Richardson, J.L.; Vepraskas, M.J.. Wetland Soils: Genesis, Hydrology, Landscapes, and Classification. Boca Raton: Lewis Publishers, 19-34, 2001.

MÉROT, P.; EZZAHAR, B.; WALERT, C.; AUROUSSEAU, P. Mapping waterlogging of soils using digital terrain models. Hydrological Processes. 9, p.27-34, 1995. DOI: http://dx.doi.org/10.1002/ hyp.3360090104

MÉROT, P.; SQUIVIDANT, H.; AUROUSSEAU; P.; HEFTING, M.; BURT, T.; MAITRE, V. KRUK, M.; BUTTURINI, A.; THENAIL, C.; VIAUD, V. Testing a climatotopographic index for predicting wetlands distribution along an European climate gradient. Ecological Modelling. 163, p.51-71, 2003. DOI: http:// dx.doi.org/10.1016/S0304-3800(02)00387-3

MOORE, I.D.; GESSLER, G.A.; PETERSON, G.A. Soil attribute prediction using terrain analysis. Soil Science Society of America Journal, 57, p.443-452, 1993. DOI: http://dx.doi.org/10.2136/ sssaj 1993.572NPb

NASH, J.E.; SUTCLIFFE, J.V. River flow forecasting through conceptual models I: a discussion of principles. Journal of Hydrology, 10, p.282-290, 1970. DOI: http://dx.doi.org/10.1016/0022-1694(70)902556

OCAMPO, C.J.; SIVAPALAN, M.; OLDHAM, C. Hydrological connectivity of upland-riparian zones in agricultural catchments: Implications for runoff generation and nitrate transport. Journal of Hydrology, 331, p.643-658, 2006. DOI: http://dx.doi. org/10.1016/j.jhydrol.2006.06.010

PIONKE, H.B.; GBUREK, W.J.; SHARPLEY, A.N. Critical source area controls on water quality in an agricultural watershed located in the Chesapeake Basin. Ecological Engineering, 14, p.325-335, 2000. DOI: http://dx.doi.org/10.1016/S0925-8574(99)00059-2

QIU,Z.A VSA-based strategy for placing conservation buffers in agricultural watersheds. Environmental Management, v. 32, p.299-311, 2003. DOI: http:// dx.doi.org/10.1007/s00267-003-2910-0

QIU, Z. Assessing Critical Source Areas in Watersheds for Conservation Buffer Planning and Riparian Restoration. Environmental Management, 44, p.968980, 2009. DOI: http://dx.doi.org/10.1007/s00267009-9380-y

QIU, Z., HALL, C., DREWES, D., MESSINGER, G., PRATO, T., HALE, K., VAN ABS, D. Hydrologically Sensitive Areas, Land Use Controls and Protection of Healthy Watersheds. J. Water Resour. Plann. Manage.: ASCE., v.140, n.7, p.2014 DOI: http:// dx.doi.org/10.1061/(ASCE)WR.1943-5452.0000376

RICHARDSON, J.L.; ARNDT, J.; MONTGOMERY, J.A. Hydrology of Wetland and Related Soils. In: Richardson, J.L.; Vepraskas, M.J.. Wetland Soils: Genesis, Hydrology, Landscapes and Classification. Boca Raton: Lewis Publishers, 35-84, 2001.

RODHE, A.; SEIBERT, J. Wetland occurrence in relation to topography: a test of topographic indices as moisture indicators. Agricultural and Forest Meteorology, 98, p.325-340, 1999. DOI: http://dx.doi. org/10.1016/S0168-1923(99)00104-5

SIEFERT, C.A.C. Delimitação de Áreas Hidrologicamente Sensíveis por meio de modelagem de processos e da relação Solo-Vegetação em ambientes hidromórficos. Dissertação (Programa de Pós-graduação em Geografia - UFPR), Curitiba: UFPR, 2012. 106p.

SIEFERT, C.A.C.; SANTOS, I. Áreas hidrologicamente sensíveis: teoria e aplicação para a bacia do rio Barigui, PR, Brasil. Revista Ambiente \& Água, v. 5, p. 61-76, 2010. DOI: http://dx.doi.org/10.4136/ambi-agua.137 
SIEFERT, C.A.C.; SANTOS, I. Mecanismos de geração de escoamento e áreas hidrologicamente sensíveis: uma abordagem hidrogeomorfológica para delimitação de áreas de preservação permanente. RA'E GA: o Espaço Geográfico em Análise, v. 24, p. 227-257, 2012. DOI: http://dx.doi.org/10.5380/raega. v24i0.26216

SPRECHER, S.W. Concepts in Soil Science. In: Richardson, J.L.; Vepraskas, M.J. Wetland Soils: Genesis, Hydrology, Landscapes and Classification. Boca Raton: Lewis Publishers, 3-19, 2001.

SRINIVASAN, M.S.; MCDOWELL, R.W. Hydrological approaches to the delineation of critical-source areas of runoff. New Zealand Journal of Agricultural Research, 50, p.249-265, 2007. DOI: http://dx.doi.org/10.1080/00288230709510293

TINER, R.W. Wetland Indicators: A Guide to Wetland Identification, Delineation, Classification, and Mapping. Boca Raton: CRC Press LLC, 2000. 424p.

TSUKAMOTO, Y. Storm discharge from an experimental watershed. Journal of the Japanese Forestry Society, 45, p.186-190, 1963.

VESTENA, L.R. Análise da relação entre a dinâmica de áreas saturadas e o transporte de sedimentos em uma bacia hidrográfica por meio de monitoramento e modelagem. Florianópolis: UFSC/CTC/ENS, 2008. 264f. Tese (Doutorado em Engenharia Ambiental) - Programa de Pós-Graduação em Engenharia Ambiental, Universidade Federal de Santa Catarina, Florianópolis, 2008.

WALTER, M.T.; WALTER M.F.; BROOKS E.S.; STEENHUIS, T.S.; BOLL, J.; WEILER, K.R. Hydrologically Sensitive Areas: Variable Source Area Hydrology Implications for Water Quality Risk Assessment. Journal of Soil and Water Conservation. v. 55, p. 277-284, 2000.

WALTER, M.T.; BROOKS, E.S.; WALTER, M.S.; STEENHUIS, T.S.; SCOTT, C.A.; BOLL, J. Evaluation of soluble phosphorus transport from manure-applied fields under various spreading strategies. Journal of Soil Water Conservation. v. 56, p.329-336, 2001.

WALTER, M.T.; ARCHIBALD, J.A.; BUCHANAN, B., DAHLKE, H., EASTON, Z.M.; MARJERISON, R.D.; SHARMA, A.N., SHAW, S.B. New paradigm for sizing riparian buffers to reduce risks of polluted storm water: practical synthesis. Journal of Irrigation and Drainage Engineering. 135, p.200-209, 2009. DOI: http://dx.doi.org/10.1061/(ASCE)07339437(2009)135:2(200) 